\title{
Propagermanium Induces NK Cell Maturation and Tends to Prolong Overall Survival of Patients With Refractory Cancer
}

\author{
SHOJIRO KIKUCHI ${ }^{1}$, KAZUMA NOGUCHI $^{2}$, KEIKO WAKAI $^{1}$, YOKO HAMAZAKI ${ }^{3}$, \\ KATSUYUKI TOZAWA ${ }^{4}$, TAKAHITO JOMORI ${ }^{5}$, MITSURU SASAKO ${ }^{6}$ and HIROTO MIWA ${ }^{4}$ \\ ${ }^{1}$ Institute for Advanced Medical Science, Hyogo College of Medicine, Nishinomiya, Japan; \\ ${ }^{2}$ Department of Oral and Maxillofacial Surgery, Hyogo College of Medicine, Nishinomiya, Japan; \\ ${ }^{3}$ Department of Life Science Frontiers, CiRA, Kyoto University, Kyoto, Japan; \\ ${ }^{4}$ Department of Medicine, Hyogo College of Medicine, Nishinomiya, Japan; \\ ${ }^{5}$ Sanwa Kagaku Kenkyusho Co., Ltd., Nagoya, Japan; \\ ${ }^{6}$ Department of Surgery, Hyogo College of Medicine, Nishinomiya, Japan
}

\begin{abstract}
Background/Aim: Propagermanium $(P G)$ inhibits the CCL2/CCR2 axis, and has been shown to function as an immune modulator. This study investigated its anti-tumor mechanism in patients with refractory cancers. Materials and Methods: Five healthy volunteers and 23 patients with refractory oral $(n=8)$ or gastric $(n=15)$ cancer received $P G$ (30 mg/day). We performed flow cytometry (FCM) of peripheral blood mononuclear cells and in vitro killing assays. Results: FCM revealed that $\mathrm{CD} 16^{+} / \mathrm{CD} 56^{\text {Dim }} \mathrm{NK}$ cells (i.e., mature, cytolytic subset) increased, and the apoptosis induction rate of cancer cells increased after $P G$ administration. Among gastric cancer patients, median $O S$ was 172.0 days. Two patients showed complete remission of lung or liver metastasis. Survival of patients with oral cancer also tended to be prolonged. Conclusion: PG induces NK cell maturation, and may potentiate anti-tumor activity.
\end{abstract}

Propagermanium (PG, 3-oxygermylpropionic acid polymer, Serocion ${ }^{\circledR}$, Sanwa Kagaku Kenkyusho, Nagoya, Aichi, Japan) is directly obtained through hydrolysis of 3-(trichlorogermyl) propanoic acid. It has been shown to function as a multifunctional immunomodulator (1). Although its mechanism is still unclear, PG activates cytotoxic T cells and natural killer (NK) cells to destroy cells infected with the hepatitis B virus, and was therefore approved in 1994 as a treatment for hepatitis B. PG is also known as an antagonist

Correspondence to: Shojiro Kikuchi, Institute for Advanced Medical Sciences, Hyogo College of Medicine, 1-1 Mukogawa-cho, Nishinomiya, Hyogo, 6638501, Japan. Tel: +81 798456229, Fax: +81 798456229, e-mail: skikuchi@hyo-med.ac.jp

Key Words: Propagermanium, gastric cancer, oral cancer, NK cells, maturation. of C-C motif chemokine receptor-2 (CCR2); it inhibits mobilization of monocytes and multiple leukocyte subsets from the bone marrow to target tissues (2). PG also attenuates diet-induced insulin resistance, adipose tissue inflammation, and non-alcoholic steatohepatitis due to its inhibition of monocyte/macrophage trafficking $(3,4)$. Moreover, PG reduces chronic colitis-associated carcinogenesis in mice by decreasing the number of infiltrating macrophages in tumors and nuclear accumulation of $\beta$-catenin in tumor cells (5).

Cancer cells secrete CC chemokine ligand-2 (CCL2), which is a ligand of CCR2. Metastatic cancer cells form a suitable environment for proliferation by attracting monocytes and bone marrow-derived stromal cells from bone marrow using the CCL2/CCR2 axis. CCL2 derived from breast cancer cells, recruits inflammatory monocytes that express CCR2 at primary tumor and metastasis sites; CCL2 neutralization in a mouse model inhibited metastasis by retaining monocytes in the bone marrow (6). In a recent study, PG showed anti-tumor effects via inhibition of the $\mathrm{C}-\mathrm{C}$ motif CCL2/CCR2 axis, even in non-inflammatory models (7). Nakayama et al. clearly showed that PG attenuated cancer metastasis as a non-specific anti-tumor effect in mouse models, because it inhibited recruitment of bone marrow-derived stromal cells (8). We hypothesized that PG administration would be a new treatment to attenuate metastasis by two different mechanisms: modification of both immune cells and the cancer microenvironment.

In past clinical studies, Tsutsumi et al. reported that PG was effective for multiple myeloma (9); and Mimori et al. confirmed its safety in Phase I trials for breast cancer (UMIN-CTR041-001). However, its immunomodulatory effects, efficacy, and safety in patients with refractory cancer have not been yet examined. The present study was a proofof-concept investigation that analyzed changes in NK cells from healthy donors (HD) treated with PG. We also 
examined the effectiveness of PG as innate immunotherapy for patients with refractory gastric or oral cancers.

\section{Materials and Methods}

Healthy donors and patients. Written informed consent was obtained from five healthy donors (HD) with no history of cancer or disease being treated. Peripheral blood was collected before, and after 4 weeks and 8 weeks (drug withdrawal) of PG administration (10 mg, three times a day [TID]) for PBMC isolation and blood testing. For the clinical study, we recruited patients with pathologically confirmed, relapsed or refractory gastric cancer (adenocarcinoma, $\mathrm{n}=15$ ) or oral cancer (squamous cell carcinoma, $\mathrm{n}=8$ ) who failed previous chemotherapies and/or could not tolerate other treatments. These cancer patients received PG (10 mg TID), for as long as possible.

All clinical samples were approved for analysis by the ethical committees of the Hyogo College of Medicine (No. 1911, March 2015-March 2019). Written informed consent was obtained from all patients with cancers analyzed in this study.

This investigation was performed as an open-labeled, singleinstitutional, single-armed, exploratory clinical study. The study was conducted in accordance with Good Clinical Practice guidelines, the ethical principles of the Declaration of Helsinki, and local regulations. This clinical study was registered at UMIN-CTR (http://.umin.ac.jp/ctr/index-j.htm), identification number UMIN000017123. Peripheral blood analysis of healthy volunteers was registered at UMIN000030952.

As historical controls, we screened survival outcomes for 47 gastric cancer patients and 15 oral cancer patients, treated with best supportive care (BSC) in Hyogo College of Medicine between Jan 04, 2008 and Dec 31, 2015. Overall survival (OS) was measured from date of final antitumor treatment to date of death in historical controls. In the patients with PG administration, OS was measured from the date of enrolment in the study until death or last followup, because four gastric cancer patients $(27 \%)$ and four oral cancer patients $(50 \%)$ did not receive any prior chemotherapy.

Sample collection. Blood samples from HD, and patients with gastric or oral cancers were collected from the HD and patients with informed consent, in accordance with the Declaration of Helsinki. Peripheral blood mononuclear cells (PBMC) were isolated by centrifugation in a heparinized tube (Vacutainer CPT ${ }^{\circledR}, \mathrm{BD}$, Franklin Lake, NJ, USA) under sterile conditions. PBMC were either used immediately or frozen $\left(1 \times 10^{6}\right.$ cells $\left./ \mathrm{ml}\right)$ in liquid nitrogen using CellBanker ${ }^{\circledR} 1$ Freezing Medium (Zenoaq, Tokyo, Japan). Mononuclear cells were collected and washed in phosphate-buffered saline twice. The serum was isolated from the peripheral blood of cancer patients $(n=16)$ and $\mathrm{HD}(n=5)$ for 3-4 weeks with PG administration, and all samples were stored at $-80^{\circ} \mathrm{C}$.

Cancer cell lines. HeLa (squamous cancer, RCB-0007) was supplied from the Riken Cell Bank (Tsukuba, Ibaraki, Japan). Cancer cell lines were maintained in RPMI1640 medium (Nacalai Tesque, Inc., Tokyo, Japan) supplemented with 10\% FBS (BioWest, Riverside, MO, USA), and 100 units $/ \mathrm{ml}$ each of penicillin and streptomycin (Gibco BRL, Paisley, UK).

Serum concentration of PG. Measurement of PG concentration by Liquid Chromatography-Mass spectrometry (LC/MS) was performed using high performance liquid chromatography (ACQUITY UPLC IClass, Waters, Milford, MA, USA) and mass spectrometry (LTQOrbitrap, Thermo Fisher Scientific, Waltham, MA, USA). Xcalibur (Thermo Fisher Scientific) was used for measurement and data analysis.

Multicolor flow cytometry. Immunofluoroscence labeled antibodies were purchased form Bio Legend (San Diego, CA, USA), BD Bioscience (Franklin Lakes, NJ, USA), and TONBO (Kobe, Hyogo, Japan). Details are shown in Table I. Fresh isolated or thawed PBMCs were stained with conjugated antibodies (NK cell panel \#1 3 protocol) for $30 \mathrm{~min}$ at $4^{\circ} \mathrm{C}$ in the dark. Stained cells were incubated with BD FACS Lysing Solution (BD Biosciences,) for 10 min to lyse red blood cells completely. After two washes, PBMCs (200,000 cells per assay) were read on an SP-6800 Spectral Cell Analyzer (SONY Biotechnology, Tokyo, Japan). Dead cells, monocytes, and T and B lymphocytes were gated out, and NK cell subsets were analyzed, based on the differential expressions of CD56 and CD16.

In vitro killing assay. HeLa cells were pre-cultured overnight with Dulbecco's Modified Eagle Medium (DMEM; Nacalai Tesque, Kyoto, Japan) in 35-mm imaging dishes with four compartments (ibidi $\mu$-Dish $35 \mathrm{~mm}$ Quad; Martinsried, Munich, Bavaria, Germany) with a volume of $600 \mu 1(5 \times 103$ cells $)$ in each well. The culture medium was then replaced with $\mathrm{F}-12 \mathrm{~K}$ nutrient mixture (Gibco Thermo Fisher, MA, USA) supplemented with 10\% (v/v) FBS. PBMCs were thawed and incubated in DMEM overnight, collected, counted, re-suspended with F-12K medium (Gibco BRL), and added to each well $\left(1 \times 10^{5}\right.$ cells). PBMCs from HD (effector cells) and HeLa cells (target cells) were co-cultured at 20:1. PBMCs collected before starting medication, at Week 4, and at Week 8 (4 weeks after drug withdrawal) were assayed at the same time and compared to control wells containing only target HeLa cells. Caspase-3/7 green reagent (5 $\mu \mathrm{M}$, IncuCyte, Essen Bioscience/ Sartorius, Ann Arbor, MI, USA) was added to each well. The coculture dishes were set into a time-lapse imaging system BioStation IM-Q (Nikon Instruments Inc., Tokyo, Japan). Time-lapse images in phase contrast and green fluorescent channel were acquired every $30 \mathrm{~min}$ for $72 \mathrm{~h}$. The number of apoptotic cancer cells was counted by a green fluorescent signal and the number of live cells was counted using the images in the phase contrast. Green fluorescent signals derived from apoptotic PBMCs were distinguished by size and excluded, using Nikon NIS elements software (Nikon Instruments Inc.).

Treatment and assessments. The patients received $30 \mathrm{mg} /$ day of PG as an oral drug, $10 \mathrm{mg}$ after each meal, for up to 1 year, or until confirmed progression, intolerable toxicity, or patient's or investigator's decision to discontinue. Patients could continue this treatment after progressive disease appeared if the following criteria were met: evidence of investigator-assessed clinical benefit; tolerance of study drug; stable performance status; treatment would not delay intervention to prevent serious complications of disease progression; and the patient provided written informed consent before continuing treatment. Treatment was repeated until the appearance of unacceptable adverse effects (AEs), or patient refusal. The PG was supplied by Sanwa Kagaku Kenkyusho Co., Ltd. (Nagoya, Aichi, Japan).

Within two weeks before commencing the study, all patients underwent computed tomography (CT) of the chest and abdomen, a complete blood cell count, and measurement of blood chemistry values. 
Table I. Immunofluorescence-labeled antibodies for multicolor flow cytometry. Upper panel: Panel \#1 3 indicates fluorescence for spectral cell analyzer and specific antigen (clone name). Lower panel: specific antigen, clone name, and manufacturer.

\begin{tabular}{|c|c|c|c|}
\hline $\begin{array}{l}\text { Panel \# } \\
\text { Fluorescence/Name }\end{array}$ & $\begin{array}{c}\# 1 \\
\text { NK cell surface }\end{array}$ & $\begin{array}{c}\# 2 \\
\text { NK cell intracellular }\end{array}$ & $\begin{array}{c}\# 3 \\
\text { NK cell isotype control }\end{array}$ \\
\hline FITC & CD69 (FN50) & GranzymeB (GB11) & Mouse IgG1k (MOPC-21) \\
\hline PE & CD3 (Hit3a) & CD3 (Hit3a) & CD3 (Hit3a) \\
\hline Ghost Dye Violet 450 & Dead cell stain & & \\
\hline PE-cy7 & CD8 (SK1) & CD8 (SK1) & CD8 (SK1) \\
\hline PerCp-cy5.5 & CD19 (HIB19) & CD19 (HIB19) & CD19 (HIB19) \\
\hline APC/ Alexa 647 & CD56 (MY31) & CD56 (MY31) & CD56 (MY31) \\
\hline APC-cy7 & CD16 (3G8) & CD16 (3G8) & CD16 (3G8) \\
\hline BV421 & CD14 (МфР9) & CD14 (МфP9) & CD14 (МфP9) \\
\hline Fluorescence & Molecule & Clone & Manufacturer \\
\hline FITC & Human CD69 & FN50 & BioLegend \\
\hline FITC & Human Granzyme B & GB11 & BD Biosciences \\
\hline FITC & Mouse IgG1 k & MOPC-21 & BioLegend \\
\hline PE & Human CD3 & Hit3a & TONBO \\
\hline $\mathrm{PE} / \mathrm{Cy} 7$ & Human CD8 & SK1 & BioLegend \\
\hline PerCP/Cy 5.5 & Human CD19 & HIB 19 & TONBO \\
\hline APC & Human CD56 & MY31 & TONBO \\
\hline $\mathrm{APC} / \mathrm{Cy} 7$ & Human CD16 & $3 \mathrm{G} 8$ & BioLegend \\
\hline BV421 & Human CD14 & $\mathrm{M} \phi \mathrm{P} 9$ & BD Biosciences \\
\hline Ghost Dye Violet 450 & $\mathrm{~N} / \mathrm{A}$ & N/A & TONBO \\
\hline
\end{tabular}

On registration day, all patients had their histories recorded, and also underwent physical examinations; measurements of body weight, blood pressure, and body temperature; and assessment of performance status. Treatment-related AEs were assessed using the Common Terminology Criteria for Adverse Events, version 4.0 (NCI-CTCAE ver.4.0). During the period of assessing AEs, physical examinations, complete blood cell counts with differential leukocyte counts, and serum chemistry assessments were performed at least every two weeks; thereafter, these assessments were carried out monthly.

Statistical analysis. Kaplan-Meier plots were used to evaluate OS The incidence of AEs was also calculated. Data were summarized as proportions and percentages for categorical variables, and as median and ranges for continuous variables. For FCM and biomarker evaluation (i.e., cell-surface and intracellular markers), categorical groups were examined using FlowJo ${ }^{\circledR}$ software version 10.6 (Ashland, OR, USA). Statistical analyses were performed using GraphPad Prism v6.01 (GraphPad Software, Inc., San Diego, CA, USA). Percentage of NK cell subsets were calculated in total NK cell at Pre, $4 \mathrm{wks}$, and $8 \mathrm{wks}$. Each sample was analyzed using the two-tailed, parametric paired t-test.

\section{Results}

Subset analysis of NK cells by oral PG administration. We used multicolor staining of PBMCs to classify $\mathrm{NK}$ cells (CD3 ${ }^{-} / \mathrm{CD} 19^{-}$lymphocytes) into four subsets according to the staining levels of CD16 and CD56. They are CD16 ${ }^{-}$CD56 ${ }^{\text {Bright }}$ (proliferative subset), CD16 $/ \mathrm{CD} 56^{\text {Bright }}$ (intermediate subset), $\mathrm{CD} 16^{+} / \mathrm{CD} 6^{\mathrm{Dim}}$ (dominant, cytolytic subset), $\mathrm{CD} 16^{+} / \mathrm{CD}^{-} 6^{-}$
$\left(\mathrm{CD} 56^{-}\right.$subset). The $\mathrm{CD} 16^{+} / \mathrm{CD} 56^{\mathrm{Dim}}$ subset is the predominant subset in peripheral blood; it has abundant granzyme B (Figure 1), which induces apoptosis against microorganisms and abnormal cells. Five HD took PG for 4 weeks; medication was withdrawn at that point and PBMCs were collected at 8 weeks. As a characteristic example, FCM of HD \#3 is shown (Figure 2). Among the 5 HDs, at Week 4, $\mathrm{CD} 16^{+} / \mathrm{CD} 6^{\mathrm{Dim}}$ subsets tended to increase (Figure $3 \mathrm{~A}$ ) and the $\mathrm{CD} 16^{+} / \mathrm{CD} 6^{\text {Bright }}$ subsets tended to decrease (Figure $3 \mathrm{~B}$ ), although not significantly so; at Week 8, their $\mathrm{CD} 16^{+} / \mathrm{CD} 6^{\text {Bright }}$ subsets were significantly decreased to levels before PG administration (Figure 3B, $p=0.474,95 \%$ $\mathrm{CI}=-8.587-0.08077)$.

Serum concentration of $P G$. After PG administration to cancer patients and HD for 3 to 4 weeks, serum PG concentration was measured by LC/MS. Serum PG concentrations did not show abnormally high values in refractory cancer patients $(n=16)$ and healthy donors $(n=5)$ in Table II. Serum PG concentration was within the range $8.2-218.0 \mathrm{ng} / \mathrm{ml}$, which is consistent with the pharmacokinetic level reported for healthy donors in the 2010 Japanese interview form of the approved medicine.

In vitro killing assay. $\mathrm{PBMCs}$ taken before and after 4 weeks of PG administration were co-cultured with HeLa cells, and apoptotic HeLa cells were counted every $30 \mathrm{~min}$. In $48 \mathrm{~h}$, apoptotic HeLa cells were indicated (Figure 4A, green 

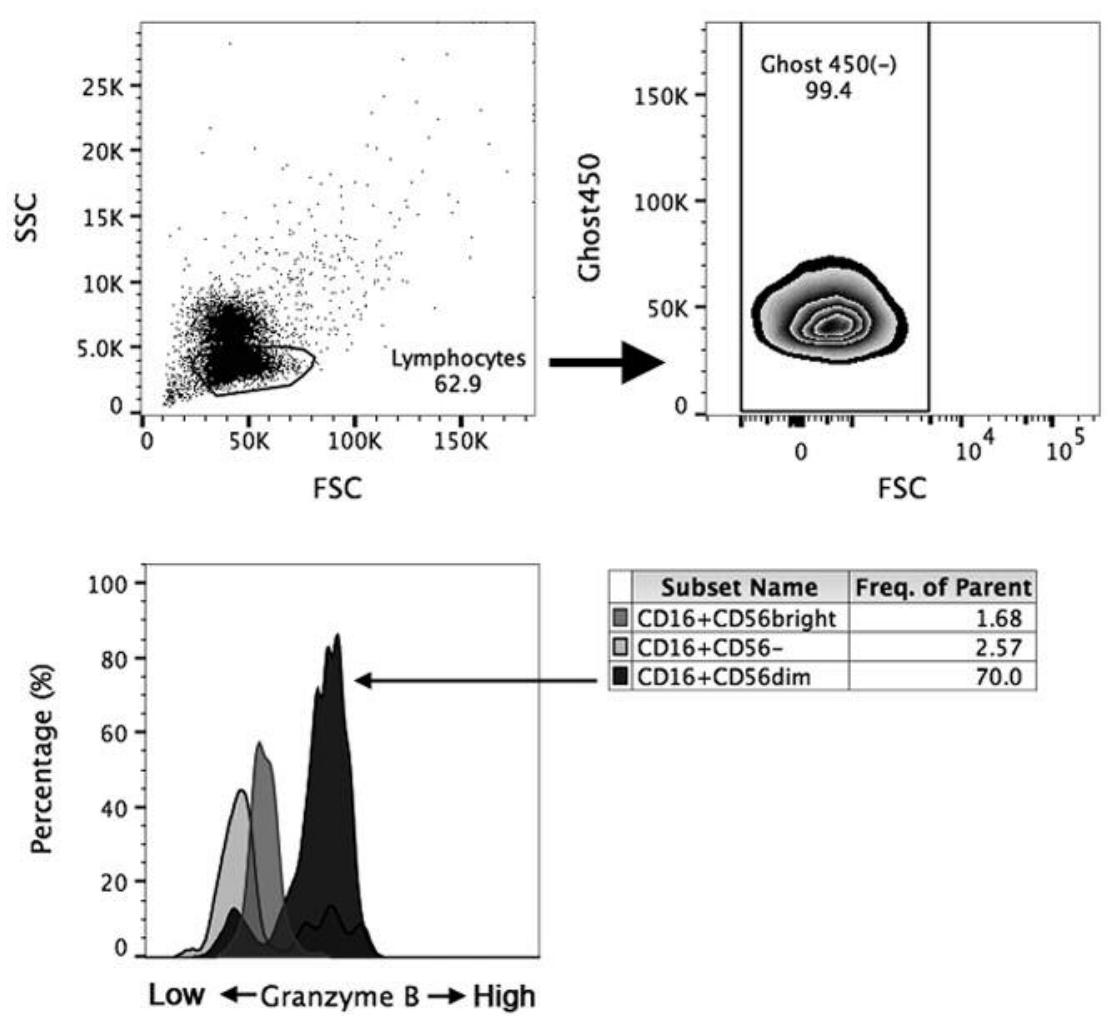
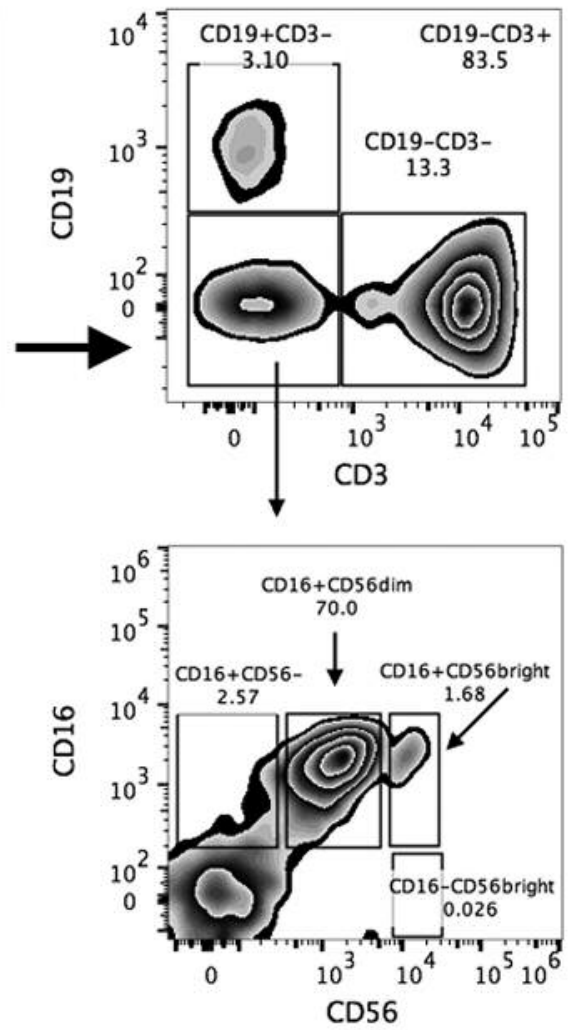

Figure 1. Subset analysis of NK cells by oral administration of propagermanium. Using multicolor staining of PBMCs, CD3-/CD19- lymphocytes were classified as NK cells into four subsets from levels of CD16 and CD56 staining. They were CD16-/CD56Bright (proliferative subset), $\mathrm{CD}^{+} / 6^{+} \mathrm{CD} 56^{\text {Bright }}$ (intermediate subset), CD16 ${ }^{+} \mathrm{CD} 56^{\text {Dim }}$ (dominant; cytolytic subset), CD16 ${ }^{+} / C D 56^{-}$(CD56-negative subset). CD16 ${ }^{+} / C D 56^{\text {Dim }}$ is the dominant subset in peripheral blood. It has abundant Granzyme B that induces apoptosis against micro-organisms and abnormal cells (left lower panel, black color).

color). Figure 4B shows the number of apoptotic HeLa cells per 1,000 cells counted every $12 \mathrm{~h}$. After PG administration, PBMCs had enhanced ability to induce apoptosis compared to Pre (no PG medication).

Characteristics of patients and AEs of PG monotherapy. Fifteen patients with advanced or relapsed refractory gastric cancer were enrolled between May 2015 and January 2017. Their median age was 78 years (range $=40-87$ years). Gender (Male: Female $=8: 7$ ) and Eastern Cooperative Oncology Group (ECOG) PS (PS 0-1, n=8 vs. PS 2, n=7) were almost equal. Nine patients $(60 \%)$ had received two or more regimens as prior treatment. All patients had multiple metastatic lesions. Safety analyses were performed in all treated patients. Anemia (grade 1-2) was reported in 10 patients $(66.7 \%)$; aspartate transaminase elevation $(40.7 \%)$, alkaline phosphatase elevation $(53.0 \%)$, constipation $(26.7 \%), \gamma$-glutamyltransferase $(40.0 \%)$, and creatinine elevation (26.7\%) were also reported. Neutropenia and autoimmune reactions were not reported among treated patients. Anemia was frequent but it did not exacerbate during PG treatment in 10 patients. One patient suspended PG treatment due to bleeding from the primary gastric cancer lesion and received irradiation to manage the bleeding.

Efficacy. The final analysis was carried out when 15 (gastric cancer) and 8 (oral cancer) events had occurred. Figure 5A, B show Kaplan-Meier curves for gastric cancer patients who received PG medication and for historical controls who received BSC. Hazard ratios (HRs) were calculated for PS 0-1 vs. PS 2 in each panel. Median OS was 172 days in the PS 0-1 group and 44 days in the PS 2 group (Figure 5A). The HR for death was 0.236 $(95 \% \mathrm{CI}=0.023-0.327, p=0.011)$ in the PS $0-1$ group. In the historical control group, median OS was 66 days in the PS $0-1$ group and 57.5 days in the PS 2 group (Figure 5B). The HR for death was $0.590(95 \% \mathrm{CI}=0.197-1.245, p=0.1519)$ in the PS 0-1 group. Figure 5C and D shows Kaplan-Meier 

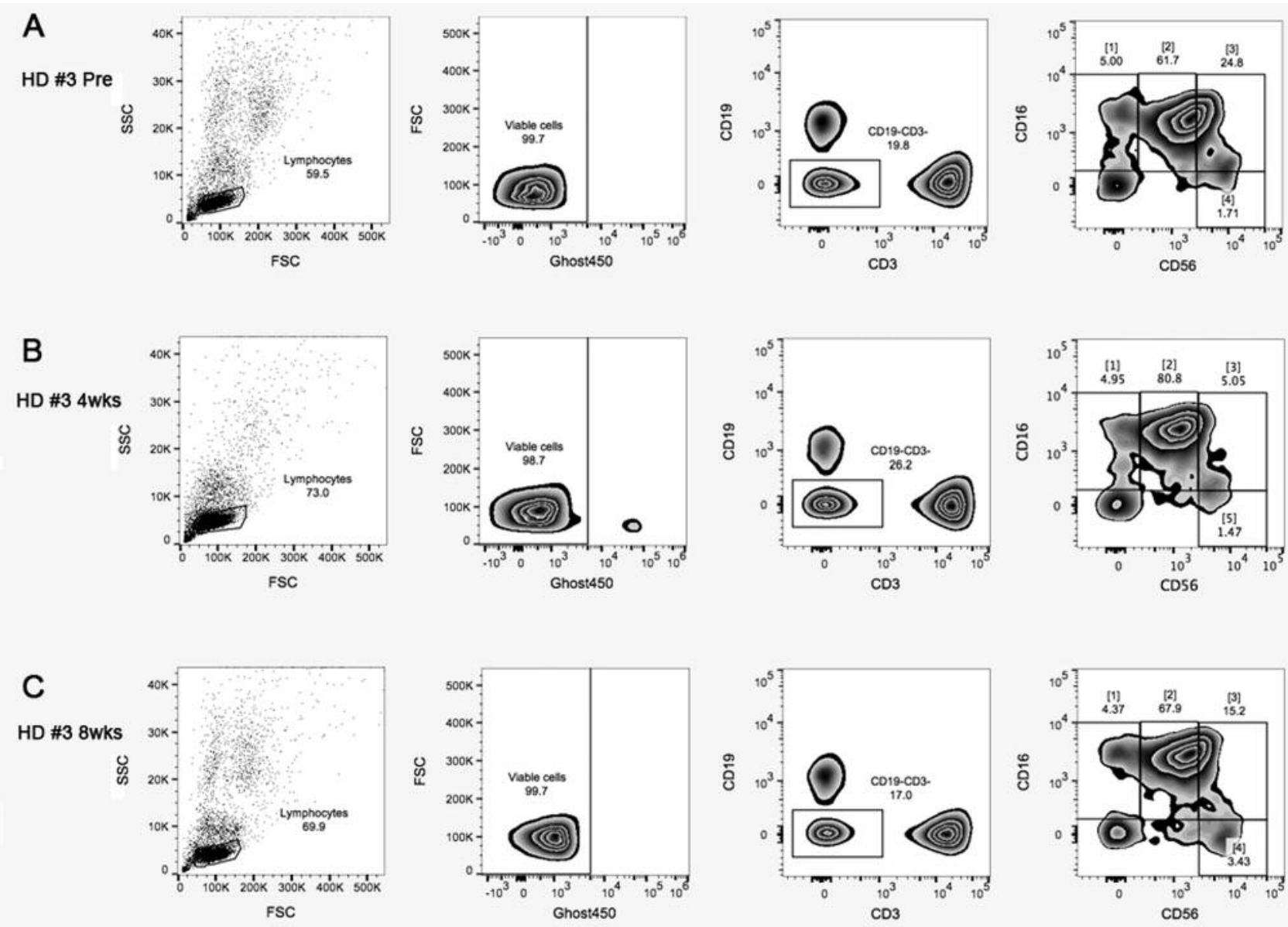

Figure 2. Transition of NK cell subset by multicolor flow cytometry (FCM) analysis. As a characteristic example, FCM of healthy donor (HD) \#3 is shown. Right column: The CD19-/CD3- subset was divided into four subsets by expression of CD16 and CD56. The CD16 ${ }^{+/ C D 56^{B r i g h t}}$ subset (shown as [3]) decreased from $24.8 \%$ (A, right panel) to $5.05 \%$ (B, right panel) after 4 weeks' medication. The CD16 $/ C D 56^{\text {Dim }}$ (cytolytic) subset (shown as [2]), increased from $61.7 \%$ (B, right panel) to $80.8 \%$ (B, right panel) after 4 weeks' medication. After 4 weeks of drug withdrawal (8wks), an intermediate subset (shown as [3]) increased to $15.2 \%$ (C, right panel).

OS curves for patients with oral cancer who received PG medication, and for historical controls who were treated with BSC. Median OS was 87.5 days in PG medication and 36.0 days in historical controls.

Figure 6 shows a complete remission of metastatic lung tumors in a patient after a total gastrectomy for advanced gastric cancer. This patient had multiple lung tumors and a small amount of pleural effusion (adenocarcinoma). In this patient, PG treatment was stopped after 12 months. Drug cessation did not induce secondary relapse after more than two years. Another objective response was observed in another patient, who had advanced gastric cancer with pyloric stenosis and multiple liver metastases (Figure 7). The stomach had expanded due to pyloric stenosis, but liver metastases were in remission after 6 weeks of PG treatment (Figure 7C, 7D).
Table II. Serum concentration of propagermanium. Patient \#1 8 (gastric cancer patients), patient \#9 16 (oral cancer patients), HD \# $1 \sim 5$ are healthy donors. $P G$ concentration in serum was measured by LC-MS after 3 4 weeks PG administration. In cancer patients, the concentration was ranged from 8.2 to $208.0 \mathrm{ng} \mathrm{eq} . / \mathrm{ml}$, which were similar to HD \#1 5 (8.3 to $218.0 \mathrm{ng}$ eq./ml).

\begin{tabular}{lrcrrr}
\hline \multicolumn{5}{c}{ Serum concentration of propagermanium (ng eq./ml) } \\
\hline Patient \#1 & 32.7 & Patient \#9 & 126.0 & HD \#1 & 218.0 \\
$\# 2$ & 12.4 & $\# 10$ & 9.7 & HD \#2 & 8.3 \\
$\# 3$ & 121.0 & $\# 11$ & 34.2 & HD \#3 & 19.0 \\
$\# 4$ & 34.9 & $\# 12$ & 97.7 & HD \#4 & 10.3 \\
$\# 5$ & 135.0 & $\# 13$ & 8.2 & HD \#5 & 18.6 \\
$\# 6$ & 61.8 & $\# 14$ & 81.3 & & \\
$\# 7$ & 78.2 & $\# 15$ & 24.1 & & \\
\#8 & 208.0 & $\# 16$ & 29.3 & & \\
Median & 70.0 & & 31.8 & & 18.6 \\
Standard deviation & 65.5 & & 44.3 & & 91.3 \\
\hline
\end{tabular}




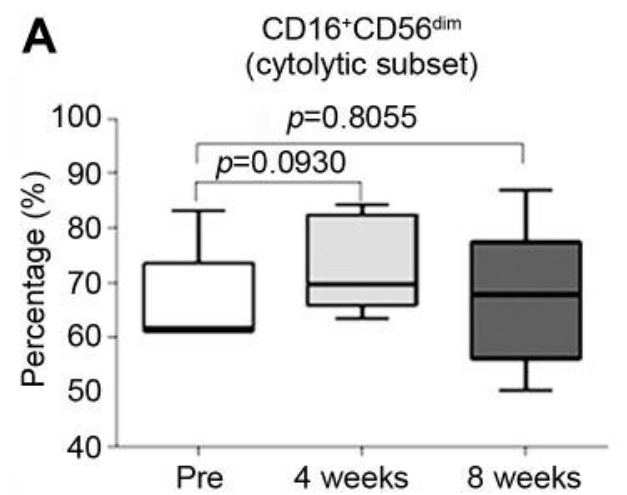

C

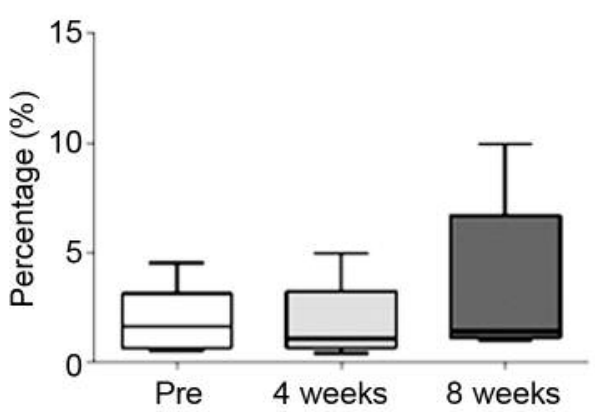

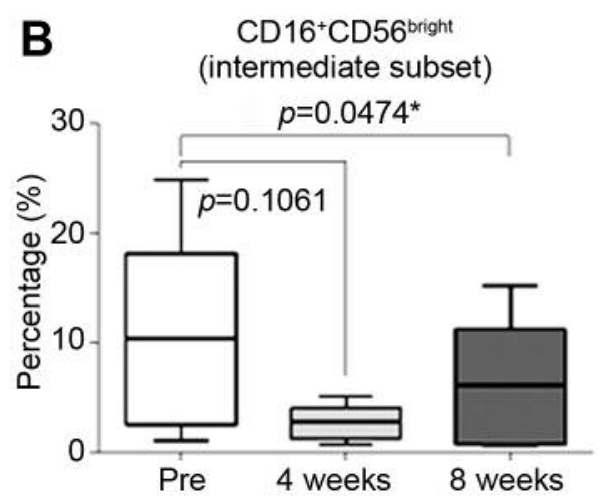

D

\section{CD16+CD56-}

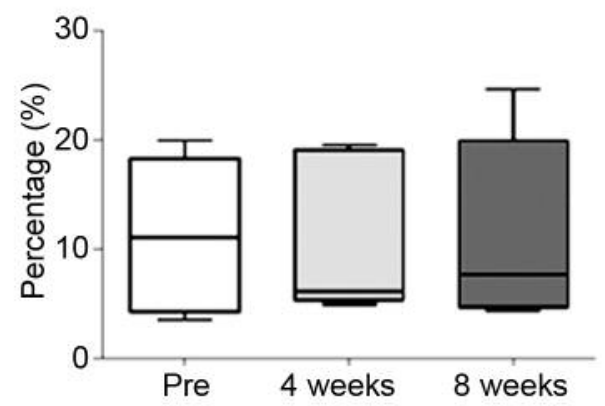

Figure 3. Transition of NK cell subsets in 5 healthy donors (HD) with no history of cancer. Subset analysis of NK cells before (Pre: white box) and after starting propagermanium (10 mg/day; TID) at 4 weeks (grey box) and 8 weeks (drug withdrawal, dark gray box). A: Cytolytic cell subsets tended to increase at 4 weeks. B: The intermediate subset decreased at 4 and 8 weeks. $C$ and D: No significant changes were observed in CD16$C D 56^{\text {Bright }}$ and $C D 16^{+} C D 56^{-}$subsets. Each datum is indicated by a bar (standard deviation) and was tested by the parametric paired t-test.

\section{Discussion}

Gastric cancer is the fifth most common cancer and the third leading cause of cancer death in the world (10). Outcomes for patients have improved because of the global application of lymph node dissection and adjuvant chemotherapy (CHT) with several drugs (11). Platinum compounds plus fluoropyrimidines are the most common first-line treatment options for patients with advanced or metastatic gastric cancer. For patients who are refractory to first-line CHT, treatment options include taxanes or irinotecan monotherapy, or the anti-vascular endothelial growth factor receptor 2 (VEGFR-2) antibody, ramucirumab, alone, or combined with taxanes (12-14). However, complete tumor remission is rare due to biological heterogeneity and malignant potential of gastric cancer, and most relapsed or metastatic cancers continue to progress even after treatment $(15,16)$. In patients treated with the BSC, OS is reportedly only 2.4-3.8 months $(17,18)$. Several candidate drugs have been tested as 3rd- line treatment, but a standard 3rd-line therapy has not been established. Recently, nivolumab, an immune checkpoint inhibitor, showed efficacy in heavily pretreated patients with advanced gastric cancer in a large phase III study (19). Nivolumab resulted in a mean OS benefit of 1.1 months over placebo in patients who had been heavily pretreated. In our study, the median OS of BSC patients with refractory gastric cancer was 172.0 days (5.7 months) and two patients showed complete remission of lung or liver metastasis. In addition, PG treatment did not present any drug-induced AEs. Most patients have uncontrolled multiple metastases, which are common causes of death.

The prognosis for intractable oral cancer is even worse. In the EXTREME trial (NCT00122460), median OS for recurrent metastatic oral cancer for which first-line CHT was ineffective was 4.4 months (20). However, few scientifically reliable data are available regarding survival of oral cancer in patients who undergo secondary CHT or palliative care. At our facility, median OS for oral cancer with BSC was 

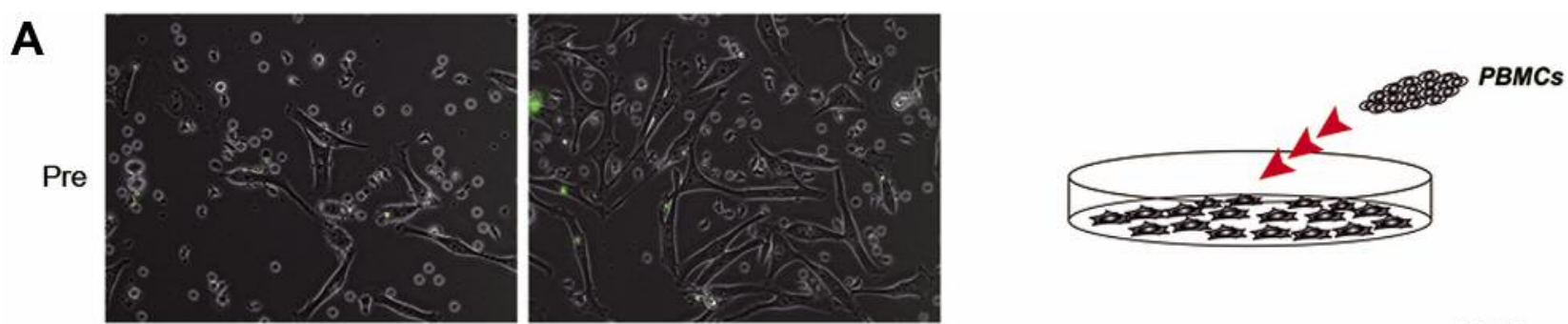

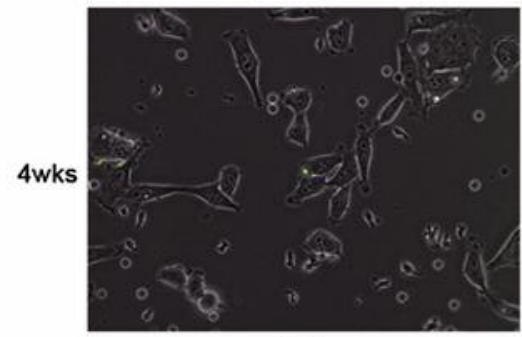

$24 \mathrm{~h}$

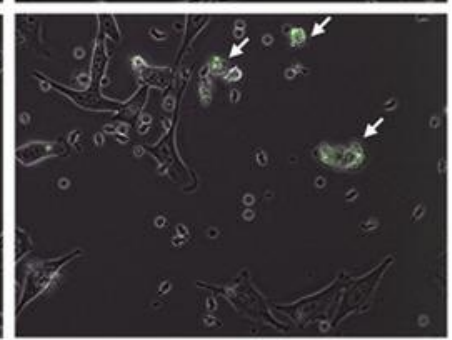

$48 \mathrm{~h}$
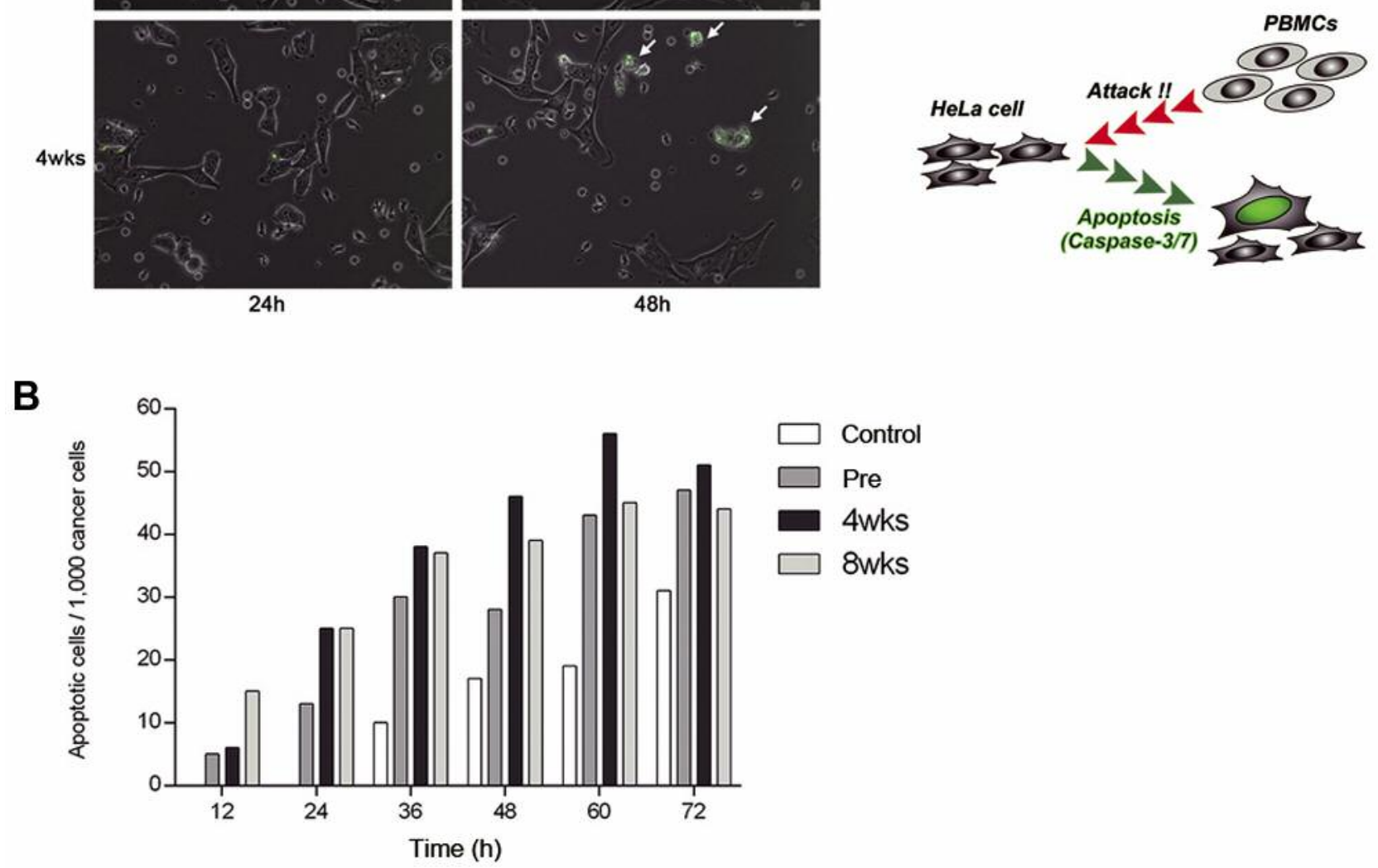

Figure 4. In vitro killing assay. PBMCs (small round cells) isolated before (Pre), after 4 weeks of propagermanium (PG) administration (4 wks), and drug withdrawal ( 8 wks) were co-cultured with HeLa cells (large, spread cells). Apoptotic cancer cells were counted every 30 min. A: After 48 h, apoptotic cancer cells were indicated (A, lower right panel, green cells indicated with white arrows). B: The number of apoptotic HeLa cells per 1,000 cancer cells every $12 \mathrm{~h}$. Each column shows control (HeLa cell alone, white), Pre (dark gray), after 4 weeks PG (black), and after 8 weeks (drug withdrawal, light gray). After PG administration, PBMCs showed enhanced ability to induce apoptosis.

36.0 days (Figure 5D). Generally, heavy, multi-drug regimens deteriorate patients' quality of life and the function of critical organs. Thus, new treatment options with fewer AEs are needed to control metastasis in these patients.

Over the 40+ years since the discovery of NK cells, their best-known function has been their ability to kill tumor cells and virus-infected cells. Their mechanism of action involves apoptosis of target cells and interaction with other immune cells and non-immune cells by cytokine and chemokine secretion (21). NK cells are a key facilitator of innate immunity and are strictly controlled by numerous activating and inhibitory receptors for maintaining immune homeostasis and pregnancy, and the ability to attack abnormal cells. For example, a mechanism for attacking cells with deficient or decreased expression of HLA-class 1 molecules of their own by "missing self" recognition is known (22). Apart from that, NK cell is classified into several subsets by the expression of CD56 (neural cell adhesion molecule, NCAM) and CD16 (also known as FcrR3); each characteristic is reportedly diverse. Differentiation of the NK cell is coupled with functional changes. The $\mathrm{CD} 16^{+} / \mathrm{CD} 56^{\mathrm{Dim}}$ subset is the most dominant and matured type in peripheral blood; it retains a large amount of the serine protease granzyme B, and was classically described as a large granular lymphocyte. The 


\section{A}

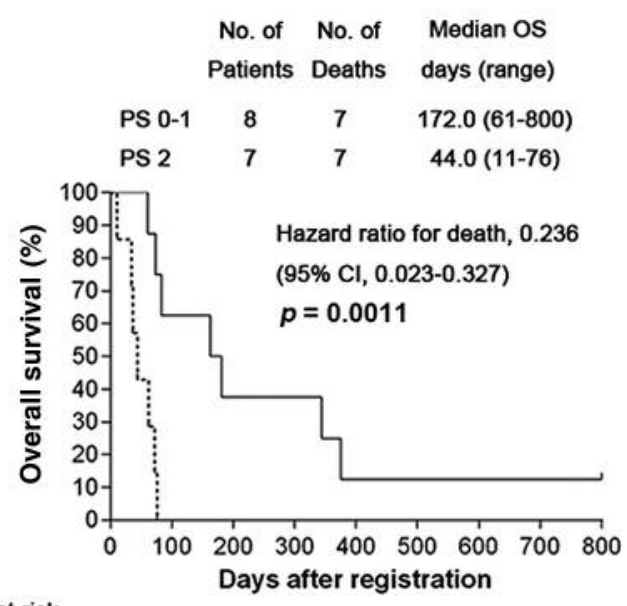

Number at risk

PS 0-1

PS 2

$\begin{array}{lllllllll}8 & 5 & 3 & 3 & 1 & 1 & 1 & 1 & 1 \\ 7 & 0 & 0 & 0 & 0 & 0 & 0 & 0 & 0\end{array}$

C

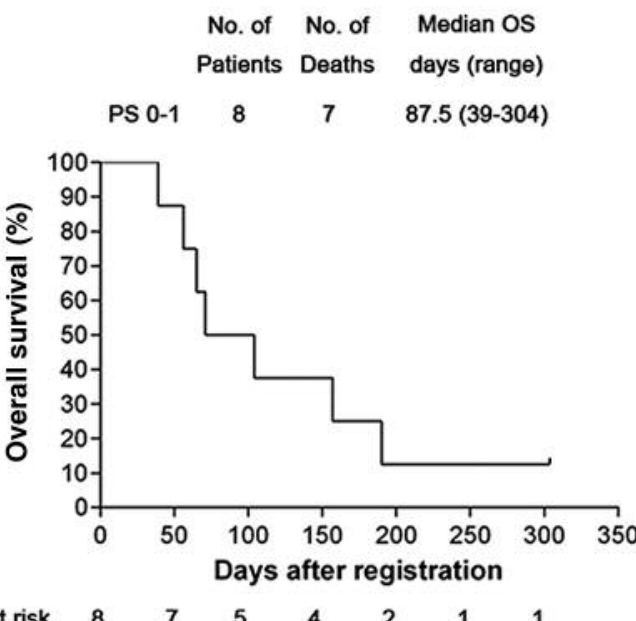

B

No. of No. of Median OS

Patients Deaths days (range)

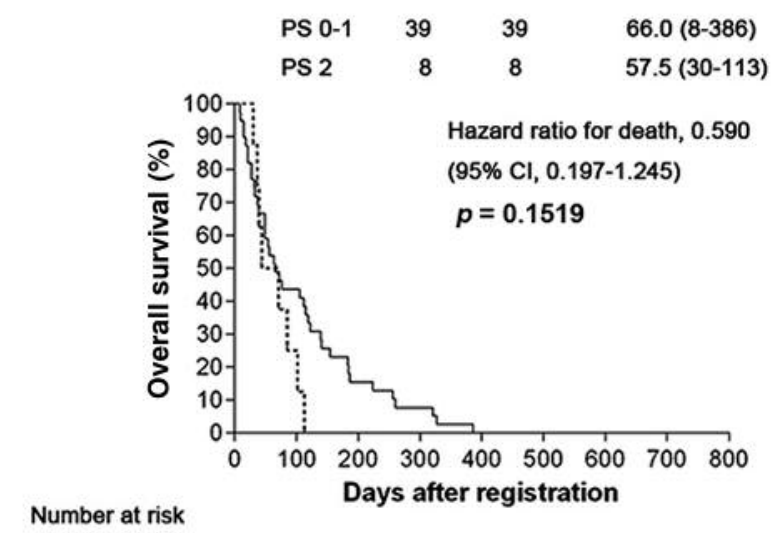

PS 0-1

$\begin{array}{ccccccccc}39 & 17 & 6 & 3 & 0 & 0 & 0 & 0 & 0 \\ 8 & 2 & 0 & 0 & 0 & 0 & 0 & 0 & 0\end{array}$

D

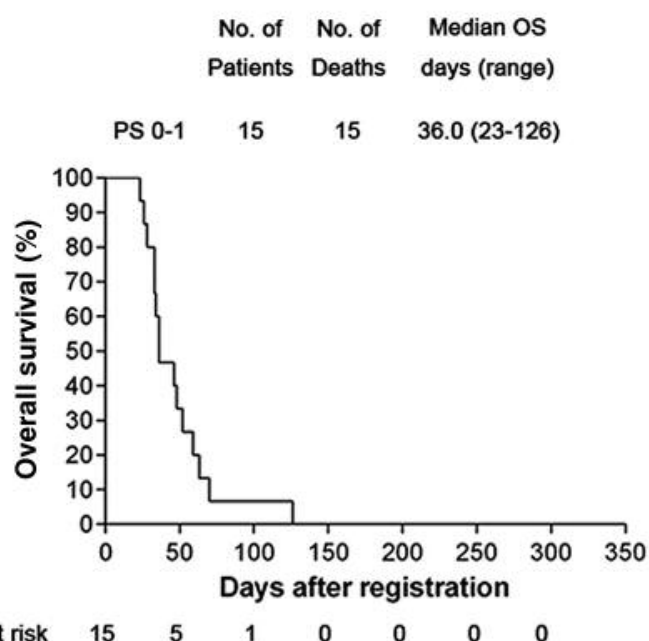

$\begin{array}{llllllll}\text { Number at risk } & 15 & 5 & 1 & 0 & 0 & 0 & 0\end{array}$

Figure 5. Clinical efficacy of propagermanium in patients with refractory gastric or oral cancers. Kaplan-Meier curve indicates overall survival of gastric cancer patients $(A$ and $B)$, and oral cancer patients $(C$ and $D)$. A: Among 15 enrolled patients with refractory advanced or relapsed gastric cancer, median OS was 172 days in the PS 0-1 group and 44 days in the PS 2 group. B: In the historical control group, median OS was 66 days in the PS 0-1 group and 57.5 days in the PS 2 group. C: Among eight enrolled patients with refractory advanced or relapsed oral cancer, median $O S$ was 87.5 days. D: In the historical control group, median OS was 36 days.

CD16-CD56 $6^{\text {Bright }}$ (immature) subset has the longest telomere and is considered to be a proliferative subset (23). Since $\mathrm{CD} 16^{+} / \mathrm{CD} 56^{\text {Bright }}$ changes to $\mathrm{CD} 16^{+} / \mathrm{CD} 56^{\mathrm{Dim}}$ in vitro, the $\mathrm{CD} 16^{+} / \mathrm{CD} 56^{\mathrm{Bright}}$ subset is considered to be a functional intermediate subset (24). Although the $\mathrm{CD} 16^{+} / \mathrm{CD} 56^{-}$subset was previously considered to be dysfunctional, Human Immunodeficiency Virus and hepatitis c virus patients have shown that the $\mathrm{CD} 16^{+} / \mathrm{CD} 56^{-}$subset produces macrophage inflammatory proteins such as CCL3, CCL4, CCL5, etc. (25). NK cells constitute a large number of diverse populations, some of which are speculated to be induced to differentiate by various developmental or environmental factors. Although NK cell biology has progressed, details regarding their differentiation and maturation in vivo are still unclear. In this study, we used flow cytometry (FCM) to analyze the in vivo effects of PG on NK cells of healthy donors.

The mature/cytolytic subset of NK cell is the dominant subset in the peripheral blood of healthy individuals. In addition, a cytolytic subset of NK cells in peripheral blood is important also in preventing blood-borne metastasis. The 

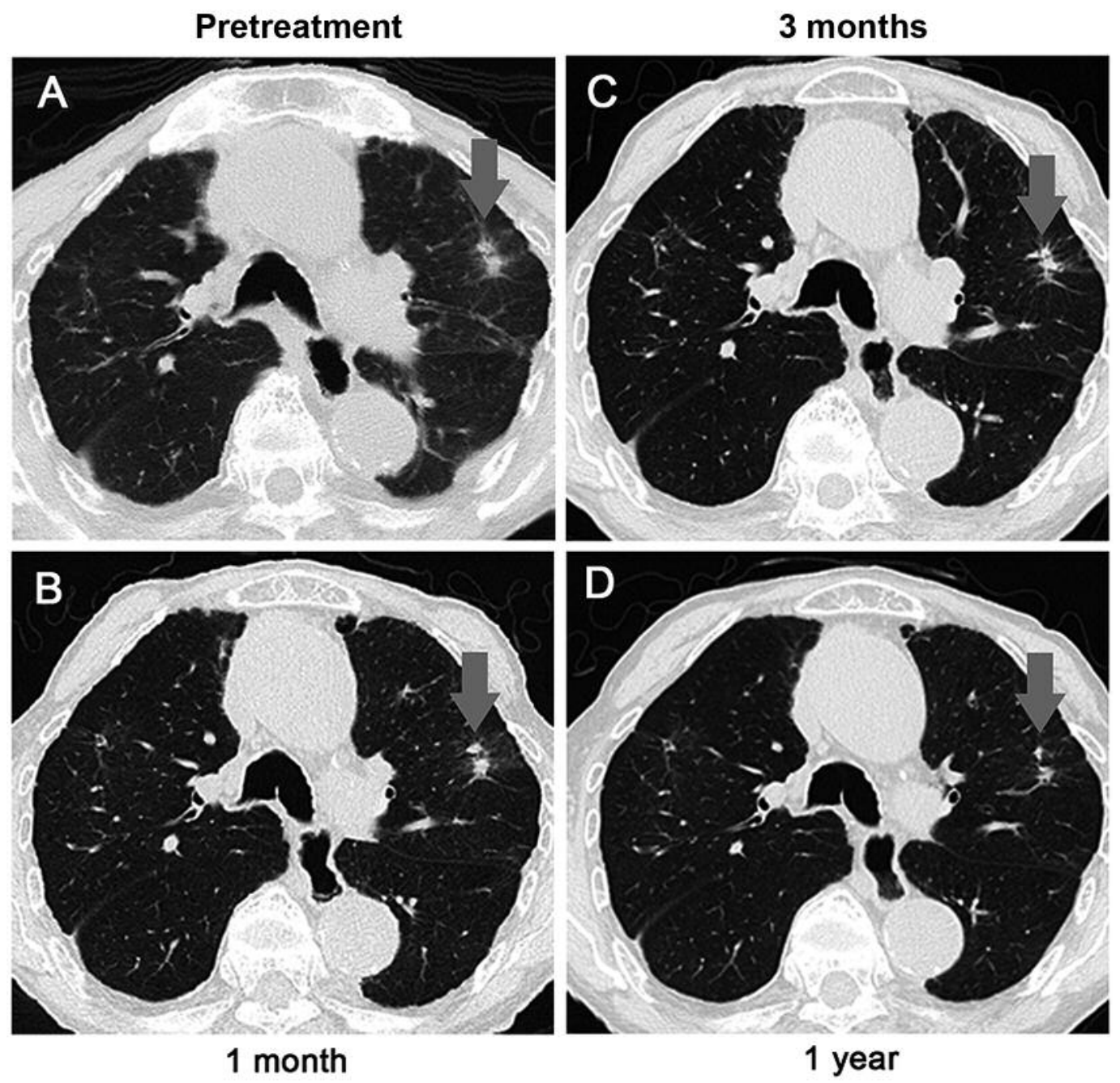

Figure 6. A: CT scan shows complete remission of metastatic lung tumors in a patient after total gastrectomy (gastric adenocarcinoma). This patient had multiple lung tumors and a small amount of pleural effusion (adenocarcinoma). Gray arrow: tumor. B, C: After receiving propagermanium, the tumor was smaller. D: Complete remission was observed at 1 year.

mechanism that links PG and NK cell maturation has not been fully elucidated. NK cells are effective in combating infections and tumors and are considered attractive for adoptive transfer therapy. Therefore, in vitro activation and expansion have been attempted, including various combinations of cytokines (26). We isolated and prepared NK cells of a HD using a MACS magnetic bead column (Miltenyi Biotec, Bergisch Gladbach, NRW, Germany) and we performed a differentiation assay with different concentrations ( $250 \mathrm{ng}-10 \mu \mathrm{g} / \mathrm{ml}$ ) of PG for 14 days. However, FCM did not show the activation or maturation of NK cells, PG did not apparently induce maturation of NK cells directly (data not shown).

We performed serial blood sampling three times prior to PG administration, for 4 weeks, and after withdrawal in $5 \mathrm{HD}$. We analyzed changes in NK cell subsets, T cells, B cells surface antigens, and activation markers by PG administration. The $\mathrm{CD} 16^{+} \mathrm{CD} 56^{\text {Bright }} \mathrm{NK}$ subset tended to decrease at week 4 after PG administration (Figure 3B, gray box), and was significantly decreased after drug withdrawal compared with before receiving PG (Figure 3B, dark gray box). The life span of NK cells is relatively long, several weeks, and the effects of PG may remain after drug withdrawal. CD $16^{+} / \mathrm{CD} 6^{\mathrm{Dim}}$ (cytolytic subset) tended to increase (although not significantly so) under PG treatment (Figure 3A). In HD \# 3, the intermediate NK subset decreased and the cytolytic NK subset increased under PG administration (Figure 2, right panels). The frozen PBMCs of HD \#3 was used to perform a killing assay on HeLa cells. As a result, the ability to induce apoptosis in cancer cells was clearly enhanced by PG. Although further detailed analysis is required, changes in the NK subset suggest PG's clinical efficacy. 

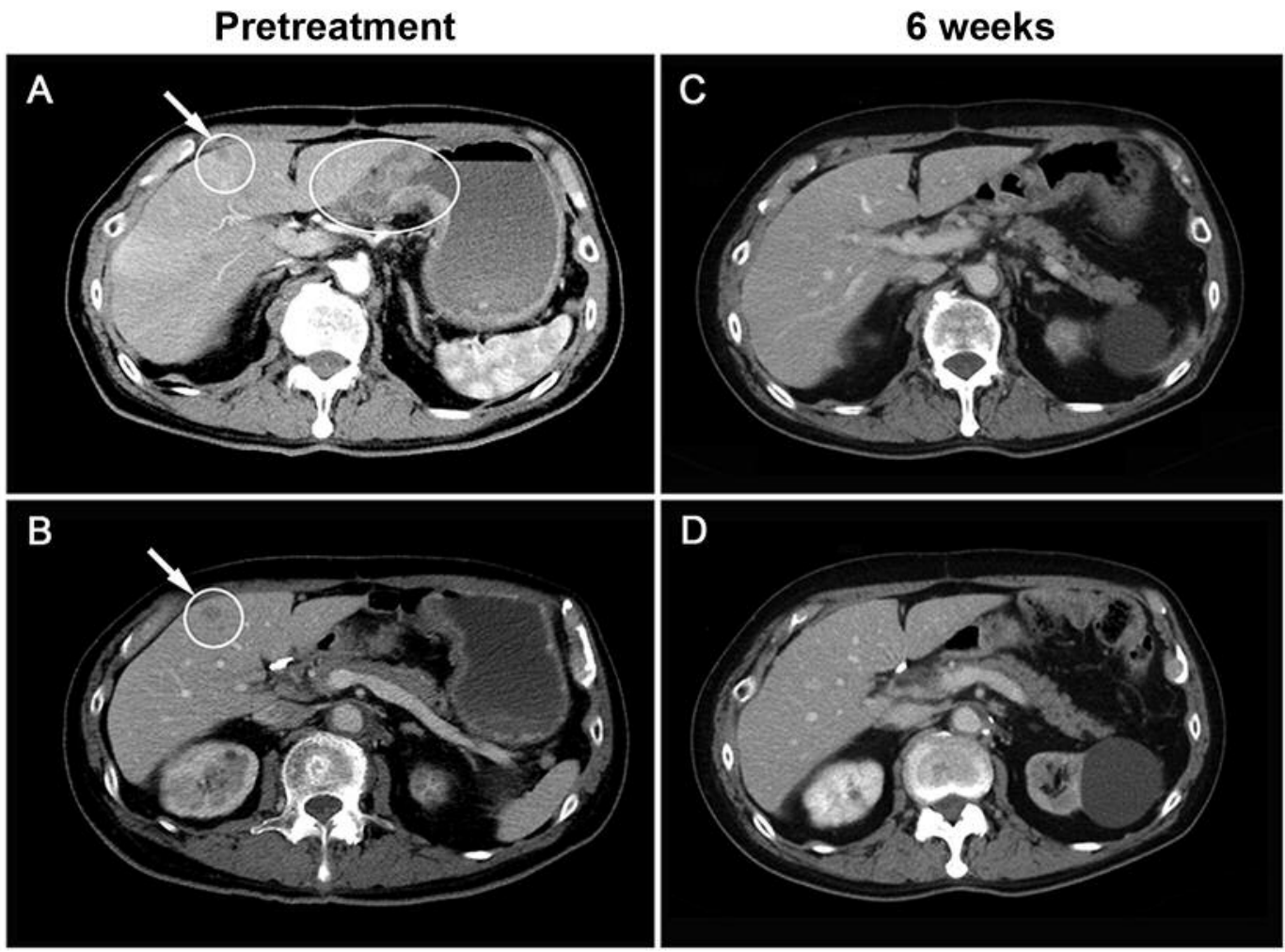

Figure 7. CT scan shows untreated advanced gastric cancer with multiple liver metastases. A, B: Before propagermanium $(P G)$ treatment. C, D: After 6 weeks' $P G$ administration. White ovals: advanced gastric cancer with pyloric stenosis; white circle: liver metastasis. Gastric cancer lesions were decreased and pyloric stenosis was reduced. Multiple liver metastases were in complete remission.

For patients with refractory cancers, after first-line CHT, combined CHT and/or molecular-targeting drugs, including immunotherapy are applied as second-line treatment. During heavy CHT, most patients suffer severely reduced quality of life from drug-induced AEs. However, even among cancer patients treated under these conditions, PG did not cause obvious AEs, and compliance was good.

In terms of cost, multi-drug regimens and molecular targeting therapies, including immune checkpoint inhibitors, are very expensive, and this is another problem for patients with refractory cancers. However, PG is a low-cost, alreadyapproved oral medicine. The cost of a regular dose $(10 \mathrm{mg}$ TID) to treat hepatitis is less than about ten dollars per day. Our clinical data showed some clinical and economic benefits of PG to treat refractory gastric and oral cancers.

As shown by Yumimoto et al., PG administration strongly suppressed lung metastasis by malignant melanoma and breast cancer through inhibition of the CCL2/CCR2 axis (7). Our data suggest that PG has an anti-tumor activity through NK cell maturation. In conclusion, PG may be effective on several cancer types, and may be a promising option for patients with refractory cancers.

\section{Conflicts of Interest}

Shojiro Kikuchi has received grants from Sanwa Kagaku Kenkyusho, and Toray Co., Ltd. T. Jomori is an advisor for Sanwa Kagaku Kenkyusho (unrestricted grant). Other Authors have no conflicts of interest.

\section{Authors' Contributions}

First author Shojiro Kikuchi collected, analysed the data along with other members of the team and formulated the whole manuscript. Kazuma Noguchi, Katsuyuki Tozawa, Mitsuru Sasako, Hiroto Miwa helped collecting the updated clinical information of the patients. Keiko Wakai conducted FCM data collection and killing assay. Yoko Hamazaki planned analysis of FCM to share data analysis. Jomori Takahito measured blood levels of PG and analyzed data of healthy volunteers.

\section{Acknowledgements}

The Authors would like to thank Nobuyuki Adachi and Ryota Shinozaki of the Hyogo College of MedicineJoint-Use Research Facilities for technical contributions. The Authors also thank Prof. TomohiroYoshimoto, Dr. Koubun Yasuda. Dr. Kohei Kometani and 
Chiyomi Inoue for flow cytometry support, and the Edanz Group (www.edanzediting.com/ac), for editing a draft of this manuscript.

Funding: This study was supported by Sanwa Kagaku Kenkyusho, and Toray Co., Ltd., and a Grant-in-Aid for Scientific Research (C) 25460466 from the Ministry of Education, Culture, Sports, Science and Technology of Japan. It was also supported by a Grant-in-Aid for Researchers, Hyogo College of Medicine, 2015 to Shojiro Kikuchi.

\section{References}

1 Yokochi S, Hashimoto H, Ishiwata Y, Shimokawa H, Haino M, Terashima Y and Matsushima K: An anti-inflammatory drug, propagermanium, may target gpi-anchored proteins associated with an mcp-1 receptor, ccr2. J Interferon Cytokine Res 21(6): 389-398, 2001. PMID: 11440636. DOI: 10.1089/107999 001750277862

2 Fujimura N, Xu B, Dalman J, Deng H, Aoyama K and Dalman RL: Ccr2 inhibition sequesters multiple subsets of leukocytes in the bone marrow. Sci Rep 5: 11664, 2015. PMID: 26206182. DOI: $10.1038 /$ srep11664

3 Tamura Y, Sugimoto M, Murayama T, Minami M, Nishikaze Y, Ariyasu H, Akamizu T, Kita T, Yokode M and Arai H: C-c chemokine receptor 2 inhibitor improves diet-induced development of insulin resistance and hepatic steatosis in mice. J Atheroscler Thromb 17(3): 219-228, 2010. PMID: 20179360. DOI: $10.5551 /$ jat. 3368

4 Ito A, Suganami T, Yamauchi A, Degawa-Yamauchi M, Tanaka M, Kouyama R, Kobayashi Y, Nitta N, Yasuda K, Hirata Y, Kuziel WA, Takeya M, Kanegasaki S, Kamei Y and Ogawa Y: Role of cc chemokine receptor 2 in bone marrow cells in the recruitment of macrophages into obese adipose tissue. J Biol Chem 283(51): 35715-35723, 2008. PMID: 18977759. DOI: 10.1074/jbc.M804220200

5 Popivanova BK, Kostadinova FI, Furuichi K, Shamekh MM, Kondo T, Wada T, Egashira K and Mukaida N: Blockade of a chemokine, ccl2, reduces chronic colitis-associated carcinogenesis in mice. Cancer Res 69(19): 7884-7892, 2009. PMID: 19773434. DOI: 10.1158/0008-5472.CAN-09-1451

6 Qian BZ, Li J, Zhang H, Kitamura T, Zhang J, Campion LR, Kaiser EA, Snyder LA and Pollard JW: Ccl2 recruits inflammatory monocytes to facilitate breast-tumour metastasis. Nature 475(7355): 222-225, 2011. PMID: 21654748. 10.1038/ nature 10138

7 Yumimoto K, Akiyoshi S, Ueo H, Sagara Y, Onoyama I, Ueo H, Ohno S, Mori M, Mimori K and Nakayama KI: F-box protein fbxw7 inhibits cancer metastasis in a non-cell-autonomous manner. J Clin Invest 125(2): 621-635, 2015. PMID: 25555218. DOI: $10.1172 / \mathrm{JCI} 78782$

8 Yumimoto $\mathrm{K}$ and Nakayama KI: Fbxw7 suppresses cancer metastasis by inhibiting niche formation. Oncoimmunology 4(8): e1022308, 2015. PMID: 26405580. DOI: 10.1080/2162402 X.2015.1022308

9 Tsutsumi Y, Tanaka J, Kanamori H, Musashi M, Minami H, Fukushima A, Yamato H, Ehira N, Kawamura T, Obara S, Ogura $\mathrm{N}$, Asaka M, Imamura $\mathrm{M}$ and Masauzi N: Effectiveness of propagermanium treatment in multiple myeloma patients. Eur J Haematol 73(6): 397-401, 2004. PMID: 15522060. DOI: 10.1111/j.1600-0609.2004.00330.x

10 Ferlay J, Soerjomataram I, Dikshit R, Eser S, Mathers C, Rebelo M, Parkin DM, Forman D and Bray F: Cancer incidence and mortality worldwide: Sources, methods and major patterns in globocan 2012. Int J Cancer 136(5): E359-386, 2015. PMID: 25220842. DOI: $10.1002 / \mathrm{ijc} .29210$

11 Shitara K, Chin K, Yoshikawa T, Katai H, Terashima M, Ito S, Hirao M, Yoshida K, Oki E, Sasako M, Emi Y and Tsujinaka T: Phase II study of adjuvant chemotherapy of s-1 plus oxaliplatin for patients with stage III gastric cancer after d2 gastrectomy. Gastric Cancer 20(1): 175-181, 2017. PMID: 26626800. DOI: 10.1007/s10120-015-0581-1

12 Wilke H, Muro K, Van Cutsem E, Oh SC, Bodoky G, Shimada Y, Hironaka S, Sugimoto N, Lipatov O, Kim TY, Cunningham D, Rougier P, Komatsu Y, Ajani J, Emig M, Carlesi R, Ferry D, Chandrawansa K, Schwartz JD, Ohtsu A and RAINBOW Study Group: Ramucirumab plus paclitaxel versus placebo plus paclitaxel in patients with previously treated advanced gastric or gastro-oesophageal junction adenocarcinoma (rainbow): A double-blind, randomised phase 3 trial. Lancet Oncol 15(11): 1224-1235, 2014. PMID: 25240821. DOI: 10.1016/S14702045(14)70420-6

13 Fuchs CS, Shitara K, Di Bartolomeo M, Lonardi S, Al-Batran SE, Van Cutsem E, Ilson DH, Alsina M, Chau I, Lacy J, Ducreux M, Mendez GA, Alavez AM, Takahari D, Mansoor W, Enzinger PC, Gorbounova V, Wainberg ZA, Hegewisch-Becker S, Ferry D, Lin J, Carlesi R, Das M, Shah MA and RAINFALL Study Group.: Ramucirumab with cisplatin and fluoropyrimidine as first-line therapy in patients with metastatic gastric or junctional adenocarcinoma (rainfall): A double-blind, randomised, placebocontrolled, phase 3 trial. Lancet Oncol 20(3): 420-435, 2019. PMID: 30718072. DOI: 10.1016/S1470-2045(18)30791-5

14 Nakamura Y, Yamanaka T, Chin K, Cho H, Katai H, Terashima M, Misawa K, Hirao M, Yoshida K, Oki E, Sasako M, Emi Y, Bando H, Kawashima Y, Fukunaga T, Gotoh M, Ishibashi T and Shitara K: Survival outcomes of two phase 2 studies of adjuvant chemotherapy with s-1 plus oxaliplatin or capecitabine plus oxaliplatin for patients with gastric cancer after $\mathrm{d} 2$ gastrectomy. Ann Surg Oncol 26(2): 465-472, 2019. PMID: 30456678. DOI: 10.1245/s 10434-018-7063-8

15 Ford HE, Marshall A, Bridgewater JA, Janowitz T, Coxon FY, Wadsley J, Mansoor W, Fyfe D, Madhusudan S, Middleton GW, Swinson D, Falk S, Chau I, Cunningham D, Kareclas P, Cook N, Blazeby JM, Dunn JA and COUGAR-02 Investigators: Docetaxel versus active symptom control for refractory oesophagogastric adenocarcinoma (cougar-02): An open-label, phase 3 randomised controlled trial. Lancet Oncol 15(1): 78-86, 2014. PMID: 24332238. DOI: 10.1016/S1470-2045(13)70549-7

16 Kang JH, Lee SI, Lim DH, Park KW, Oh SY, Kwon HC, Hwang IG, Lee SC, Nam E, Shin DB, Lee J, Park JO, Park YS, Lim HY, Kang WK and Park SH: Salvage chemotherapy for pretreated gastric cancer: A randomized phase III trial comparing chemotherapy plus best supportive care with best supportive care alone. J Clin Oncol 30(13): 1513-1518, 2012. PMID: 22412140. DOI: $10.1200 / J C O .2011 .39 .4585$

17 Thuss-Patience PC, Kretzschmar A, Bichev D, Deist T, Hinke A, Breithaupt K, Dogan Y, Gebauer B, Schumacher G and Reichardt P: Survival advantage for irinotecan versus best supportive care as second-line chemotherapy in gastric cancer-a randomised phase III study of the arbeitsgemeinschaft internistische onkologie (aio). Eur J Cancer 47(15): 2306-2314, 2011. PMID: 21742485 DOI: 10.1016/j.ejca.2011.06.002

18 Liguigli W, Tomasello G, Toppo L, Ratti M and Passalacqua R: Ramucirumab for metastatic gastric or gastroesophageal junction 
cancer: Results and implications of the regard trial. Future Oncol 10(9): 1549-1557, 2014. PMID: 25145426. DOI: 10.2217/ fon.14.106

19 Kang YK, Boku N, Satoh T, Ryu MH, Chao Y, Kato K, Chung HC, Chen JS, Muro K, Kang WK, Yeh KH, Yoshikawa T, Oh SC, Bai LY, Tamura T, Lee KW, Hamamoto Y, Kim JG, Chin K, Oh DY, Minashi K, Cho JY, Tsuda M and Chen LT: Nivolumab in patients with advanced gastric or gastro-oesophageal junction cancer refractory to, or intolerant of, at least two previous chemotherapy regimens (ono-4538-12, attraction-2): A randomised, double-blind, placebo-controlled, phase 3 trial. Lancet 390(10111): 2461-2471, 2017. PMID: 28993052. DOI: 10.1016/S0140-6736(17)31827-5

20 Vermorken JB, Mesia R, Rivera F, Remenar E, Kawecki A, Rottey S, Erfan J, Zabolotnyy D, Kienzer HR, Cupissol D, Peyrade F, Benasso M, Vynnychenko I, De Raucourt D, Bokemeyer C, Schueler A, Amellal N and Hitt R: Platinumbased chemotherapy plus cetuximab in head and neck cancer. $\mathrm{N}$ Engl J Med 359(11): 1116-1127, 2008. PMID: 18784101. DOI: 10.1056/NEJMoa0802656

21 Vivier E, Tomasello E, Baratin M, Walzer T and Ugolini S: Functions of natural killer cells. Nat Immunol 9(5): 503-510, 2008. PMID: 18425107 . DOI: $10.1038 /$ ni1582

22 Karre K, Ljunggren HG, Piontek G and Kiessling R: Selective rejection of h-2-deficient lymphoma variants suggests alternative immune defence strategy. Nature 319(6055): 675-678, 1986. PMID: 3951539. DOI: $10.1038 / 319675 \mathrm{a} 0$
23 Ouyang Q, Baerlocher G, Vulto I and Lansdorp PM: Telomere length in human natural killer cell subsets. Ann N Y Acad Sci 1106: 240-252, 2007. PMID: 17303822. DOI: 10.1196/annals. 1392.001

24 Beziat V, Duffy D, Quoc SN, Le Garff-Tavernier M, Decocq J, Combadiere B, Debre P and Vieillard V: Cd56brightcd16+ nk cells: A functional intermediate stage of nk cell differentiation. J Immunol 186(12): 6753-6761, 2011. PMID: 21555534. DOI: 10.4049/jimmunol.1100330

25 Bjorkstrom NK, Ljunggren HG and Sandberg JK: Cd56 negative nk cells: Origin, function, and role in chronic viral disease. Trends Immunol 31(11): 401-406, 2010. PMID: 20829113. DOI: $10.1016 / \mathrm{j}$.it.2010.08.003

$26 \mathrm{Wu} \mathrm{Y,} \mathrm{Tian} \mathrm{Z} \mathrm{and} \mathrm{Wei} \mathrm{H:} \mathrm{Developmental} \mathrm{and} \mathrm{functional} \mathrm{control}$ of natural killer cells by cytokines. Front Immunol 8: 930, 2017. PMID: 28824650. DOI: 10.3389/fimmu.2017.00930
Received July 2, 2019

Revised July 10, 2019

Accepted July 11, 2019 